\title{
Conservative Interventions for mobile Pes Planus in Adults: a systematic review
}

\author{
Robert L AshFORD ${ }^{1,2}$, Ian MATHIESON ${ }^{3}$, Keith RoME $^{4}$ \\ ${ }^{1}$ Faculty of Health, Birmingham City University, Birmingham, UK. \\ Robert.Ashford@bcu.ac.uk \\ ${ }^{2}$ Institute for Work Based Learning, Middlesex University, London, UK. \\ ${ }^{3}$ School of Health Sciences, Cardiff Metropolitan University, Cardiff, UK. \\ IMathieson@cardiffmet.ac.uk \\ ${ }^{4}$ Division of Rehabilitation \& Occupation Studies, AUT University, Auckland 1020, New Zealand \\ Keith.rome@aut.ac.nz
}

\author{
Correspondencia: \\ Prof Dr. Robert L Ashford \\ Birmingham City University \\ Faculty of Health,Education and Life Science \\ City South Campus \\ Birmingham, B15 3TN \\ United Kingdom
}

Fecha de recepción: 10 de noviembre de 2015

Fecha de aceptación: 19 de marzo de 2016

Los autores declaran no tener ningún tipo de interés económico o comercial.

\begin{abstract}
Background. Adult pes planus (flat foot) is a common problem encountered by many health care professionals. Despite the perception that flat foot can cause pain and impair function, and the availability and widespread use of various treatments, there is no consensus on the optimal treatment strategy. Aim. To assess the effectiveness of conservative (non-surgical) interventions for pes planus in adults. Method. A systematic search of the literature was undertaken. This included: the Cochrane Central Register of Controlled Trials; the CMSG Specialized Trials Register; an electronic search was conducted using MEDLINE (1960 to June 2012), EMBASE (1980 to June 2012), and CINAHL (1982 - June 2012). Specialised journals, trial reference lists and review articles were hand searched.

Selection criteria: Randomised or quasi-randomised trials of treatment interventions for pes planus in adults. Trials that included specific pathologies such as plantar heel pain, metatarsal stress fractures, posterior-tibial tendon dysfunction, ankle fractures, rheumatoid foot pathologies, neuromuscular conditions and diabetic foot complications were excluded. Data collection and analysis: Two authors independently screened the search results to identify those meeting the inclusion criteria and quality assessed those included using a checklist based on the Cochrane Collaboration Assessment of Risk of Bias tool. This tool focused on risk of selection, performance, detection, attrition and reporting bias. Results. Four trials, involving 140 subjects, met the inclusion criteria for the review. All four were judged to be at high risk of bias in at least one area, and were also at unclear risk of bias in at least one other area. All scored highly in relation to attrition bias, due to the short follow up times and experimental designs used. Data was not pooled due to the high level of heterogeneity identified in the interventions assessed, participants selected and outcomes measured. The results of one study suggest that after four weeks of use orthoses may result in a significant improvement in medio lateral sway, and may result in improved, although non-significant, general foot-related quality of life (Rome 2004). One study (Redmond 2009) suggests that their effect on plantar pressure distribution in the foot may not be dependent on whether they are custom or prefabricated devices. Although this study identified significant changes in some plantar pressure variables with both custom and prefabricated devices, another (Esterman 2005) failed to find any significant effect of $3 / 4$ length prefabricated orthoses on pain, injury incidence, foot health or quality of life in a group of air force recruits. The fourth study (Jung 2009) suggests that exercising the intrinsic foot muscles may enhance the effect of orthoses. Despite these findings, since each study incurred risk of bias in at least one area no conclusions can be drawn.
\end{abstract}

Key words: Adult pes planus; Flatfeet; Systematic Review. 


\section{RESUMEN}

Antecedentes. Pes Adulto planus (pie plano) es un problema común encontrado por muchos profesionales de la salud. A pesar de la percepción de que el pie plano puede causar dolor y deteriorar su función, la disponibilidad y el uso generalizado de diversos tratamientos, no hay consenso sobre la estrategia óptima de tratamiento. Objetivo. Evaluar la efectividad de las intervenciones conservadoras (no quirúrgicos) para pie plano en los adultos. Método. Se realizó una búsqueda sistemática de la literatura. Esto incluye: el Registro Cochrane Central de Ensayos Controlados; los Juicios CMSG Especializados Registro; una búsqueda electrónica se realizó utilizando MEDLINE (1960 a junio de 2012), EMBASE (1980 a junio de 2012), y CINAHL (1982 - junio de 2012). Revistas especializadas, listas de referencias de ensayos y artículos de revisión se realizaron búsquedas manuales. Criterios de selección: Ensayos aleatorios o cuasialeatorios de intervenciones de tratamiento para el pie plano en los adultos. Se excluyeron los ensayos que incluyeron patologías específicas como el dolor plantar del talón, las fracturas por sobrecarga de los metatarsianos, disfunción del tendón tibial posterior-, fracturas de tobillo, patologías del pie reumatoide, enfermedades neuromusculares y las complicaciones del pie diabético. Recopilación y análisis de datos: Dos autores seleccionaron de forma independiente los resultados de la búsqueda para identificar a aquellos que satisfacen los criterios de inclusión y evaluaron la calidad de los incluidos mediante una lista de control basado en la Evaluación de la Colaboración Cochrane de Riesgo. Esta herramienta se centró en el riesgo de la selección, el rendimiento, la detección, la heterogeneidad y el sesgo de notificación. Resultados. Cuatro ensayos, con 140 sujetos, cumplieron los criterios de inclusión para la revisión. Los cuatro fueron juzgados como de alto riesgo de sesgo en al menos un área, y también estaban en riesgo de sesgo incierto en al menos otra zona. Todos anotaron altamente en relación al sesgo de deserción, debido al corto seguimiento tiempos y diseños experimentales utilizados. Los datos no se agruparon debido al alto nivel de heterogeneidad identificada en las intervenciones evaluadas, los participantes seleccionados y medir los resultados. Los resultados de un estudio sugieren que después de cuatro semanas de uso ortesis puede resultar en una mejora significativa en vaivén lateral medio, y pueden resultar en una mejor, aunque no significativa, en general relacionados con la calidad de vida de los pies (Roma 2004). Un estudio (Redmond 2009) sugiere que su efecto sobre la distribución de la presión plantar en el pie puede no depender de si son personalizados o dispositivos prefabricados. Aunque este estudio se identificaron cambios significativos en algunas variables de presión plantar tanto con la costumbre y dispositivos prefabricados, otro (Esterman 2005) no encontró ningún efecto significativo de longitud $3 / 4$ ortesis prefabricadas sobre el dolor, la incidencia de lesiones, salud pie o de calidad de vida en un grupo de reclutas de la fuerza aérea. El cuarto estudio (Jung 2009) sugiere que el ejercicio de los músculos intrínsecos del pie puede mejorar el efecto de las ortesis. A pesar de estos resultados, ya que cada estudio incurrió riesgo de sesgo en al menos un área no se pueden sacar conclusiones.

Palabras clave: pes planus; Pie plano; revisión sistemática.

Referencia normalizada: Ashford RL, Mathieson I, Rome K. Conservative Interventions for mobile Pes Planus in Adults: a systematic review. Rev. Int. Cienc. Podol. 2016; 10(2): 42-61.

Sumario: 1. Introduction. 2. Aim. 3. Methods. 4. Results. 5. Discussion. 6. Conclusion. References. 


\section{INTRODUCTION}

Pes Planus is a descriptive term that encompasses both flexible and rigid flatfeet. It is a common condition that has been recognized for many years, yet its natural history has never been investigated. It is assumed to be detrimental to function and to be associated with pain, although it is not straightforward to identify those flatfeet that will, and will not, develop symptoms nor to predict what those symptoms will be. Flat feet are commonly associated with a range of pathological conditions affecting the foot - for example painful arches or symptomatic callosities ${ }^{5}$ - and the proximal musculoskeletal skeletal chain - for example Achilles tendinopathy or patellofemoral pain ${ }^{6}$. This is despite the lack of a universally accepted definition of normal arch height within the general population $^{7}$, and a lack of valid clinical or radiographic definitions ${ }^{8}$. Current classification systems provide broad guidelines for treating flat feet, essentially classifying it as normal, flexible, or rigid, as well as separating out tibialis posterior tendon dysfunction ${ }^{9}$. Where the flat foot is rigid, restoration of alignment and function is impossible, but in the mobile or flexible flatfoot - where a normal arch can be seen when non-weight bearing - there exists the potential to utilize a range of treatments to improve structure and function, to alleviate symptoms. In the absence of good quality information, approaches to management have developed through experience, observation, and theoretical assumptions, and there are many professional champions who advocate specific, sometimes esoteric, treatment regimes.

Treatment choices are based on clinical information and an eclectic evidence base that reports on a plethora of treatments ranging from conservative to surgical treatments. In the first instance conservative treatments are typically used, including advice ${ }^{10-14}$, stretching, footwear modifications ${ }^{15}$ and strapping ${ }^{16}$. Despite the widespread and common use of a range of treatments there is no consensus regarding the optimal approach.

\section{AIM}

The aim of this review was to evaluate evidence from controlled trials of conservative treatments for mobile pes planus in adults, to identify the optimal treatment strategy.

\section{METHODS}

\section{Criteria for considering studies for this review}

\section{Types of studies}

Any randomised, quasi-randomised or controlled clinical trial meeting the specifications for participants, intervention or outcomes listed below were eligible for inclusion.

\section{Types of participants}

Inclusion in this review was restricted to trials with participants meeting the following inclusion criteria:

1. Adults $>16$ years of age.

2. Mobile pes planus pain for greater than 3 weeks duration.

3. A satisfactory system, using previously reported techniques, for diagnosing mobile pes planus.

4. No history of significant trauma or systemic inflammatory condition such as rheumatoid arthritis.

5. Studies of various soft tissue conditions or pain due to tendinopathy / tendinitis at all sites were deemed eligible provided that the pes planus pain results were presented separately or $>90 \%$ of participants in the study had pes planus pain.

\section{Exclusion criteria}

Any study that reported in isolation a specific diagnosed condition such as heel pain, stress fractures of the metatarsals, posterior tibial tendon dysfunction, ankle fractures, rheumatoid foot pathologies, neuromuscular conditions and diabetic foot pathology was excluded.

\section{Types of Interventions}

- Any rigid, semi-regid or soft foot orthoses designed to manage mobile pes planus through re-allingment and/or pain reduction

- Anti-pronatory strapping.

- $\quad$ Stretching exercises 
- Footwear modification

- Foot health promotion

\section{Types of outcome measures}

Primary outcomes:

- Quantifiable measures of pain (e.g. visual analogue scale)

- Quantifiable measures of function or alignment

- Quality of life

- Adverse effects

\section{Other outcomes:}

- Patient satisfaction

- Measures of shoe wear mark distribution

- Comfort

- Satisfaction

\section{Search methods for identification of studies}

Studies to be considered for the Review were sought from the Cochrane Central Register of Controlled Trials (CENTRAL).The CMSG Specialized Trials Register was also accessed. An electronic search was conducted using MEDLINE, EMBASE, CINAHL, Index to Theses, Dissertation Abstracts and Current Contents. In MEDLINE the optimum search strategy for randomised trials described by Robinson ${ }^{17}$ was used with the specific search terms and strategy presented below.

The electronic search was complemented by hand searches of:

- Bibliographic references of identified studies

- Current Contents up to June 2012 (to identify studies not yet indexed in MEDLINE)

- Abstracts published in special issues of specialised journals or in conference proceedings.

Reference lists were hand searched for additional studies reported in published papers, presentations at scientific meetings, and personal communications. Content experts were contacted for additional studies and unpublished data.

In MEDLINE the optimum search strategy for randomised trials described by Robinson ${ }^{17}$ was used with the following specific search terms:

1 exp Flatfoot/ (966)

2 flat foot\$.mp. (156)
3 flatfoot\$.mp. (1016)

4 flat feet.mp. (106)

5 flatfeet.mp. (37)

6 pes planus.mp. (146)

7 painful foot.mp. (57)

8 pes planovalgus.mp. (36)

9 posterior tibial tendon dysfunction.mp. (86)

10 or/1-9 (1267)

11 randomized controlled trial.pt. (188086)

12 controlled clinical trial.pt. (66155)

13 randomized controlled trials.sh. (32035)

14 random allocation.sh. (50531)

15 double blind method.sh. (77825)

16 single-blind method.sh. (8032)

17 clinical trial.pt. (380807)

18 clinical trials.sh. (114062)

19 clinical trial.tw. (29898)

20 ((singl\$ or doubl\$ or trebl\$ or tripl\$) and (mask\$ or blind\$)).tw. (79643)

21 placebos.sh. (22956)

22 placebo\$.tw. (83635)

23 random\$.tw. (282433)

24 Research Design/ (37786)

25 comparative study.sh. (1114320)

26 evaluation studies.sh. (114841)

27 follow-up studies.sh. (282159)

28 prospective studies.sh. (172213)

29 control\$.tw. (1236021)

30 prospectiv\$.tw. (176671)

31 volunteer\$.tw. (83301)

32 or/11-31 (2936912)

33 (animal not human).mp. (89340)

3432 not 33 (2904240)

3510 and 34 (275)

The electronic search was complemented by hand-searches of the following.

1. Bibliographic references of identified studies.

2. Current Contents up to April 2007 (to identify articles not yet indexed in MEDLINE).

3. Abstracts published in special issues of specialised journals or in conference proceedings.

4. Reference lists were hand-searched for additional studies reported in published papers, presentations at scientific meetings, and personal communications.

5. Content experts were contacted for additional studies and unpublished data. 


\section{Data collection and analysis}

\section{Study identification}

Titles and abstracts were identified by searching appropriate resources and were read by two reviewers. Full papers of reports of potentially eligible trials were obtained for full assessment for inclusion, from which a list of eligible trials was devised. Details of excluded studies, with the rationale for exclusion, were gathered during this process. The two principal reviewers discussed inclusions and exclusions, and a third reviewer was available for dispute resolution.

\section{Quality assessment}

Methodological assessment was undertaken by two reviewers independently. Results were compared and discussed, and a 3rd reviewer acted as arbiter in the event of dispute. Domain- based evaluation of the included papers, focusing explicitly on assessment of risk of bias, was undertaken in accordance with the recommendations of the Cochrane Handbook for Systematic Reviews of Interventions Version 5.1.0 (Higgins \& Green 2011)21. This focused on the areas of selection, performance, detection, attrition and reporting bias, with other sources of potential bias considered in the context of the individual studies included. This tool was selected over quality assessment tools, such as the Jadad $(1996)^{22}$ scale, is it overcomes the issue of judging quality based on level of reporting as opposed to the rigour (methodological quality) with which the study was conducted.

\section{Data extraction}

Data extraction and assessment of risk of bias involved completing a custom form designed for the purpose, which followed the guidelines issued by the Cochrane Handbook for Systematic Reviews of Interventions http://handbook.cochrane.org/

\section{Data analysis}

Despite an intention to utilize a variety of data analysis techniques, including assessment of study homogeneity and the derivation of rules for the assessment of continuous / dichotomous data and for data pooling, the low numbers of eligible studies and the diversity of the outcome measures reported precluded this. The focus, therefore, was a narrative account of results.

\section{RESULTS}

\section{Description of studies}

See: Characteristics of included studies / Characteristics of excluded studies (Tables 2-5/ Table 6)

Eighteen studies were identified, of which 14 were excluded for a variety of reasons that are listed under 'excluded studies', but are dominated by their focus on experimental designs in which no randomisation or control procedure was utilised. Reasons for exclusion are included in the Characteristics of Excluded Studies.

Four studies of interventions for mobile pes planus in adults were included in this review: Rome (2004) $)^{1}$; Esterman (2005) ${ }^{3}$, Redmond $(2009)^{2}$ and Jung et al $(2011)^{4}$. All recruited low numbers of subjects - Rome $n=50$, Esterman $\mathrm{n}=47$, Redmond $\mathrm{n}=15$, Jung $\mathrm{n}=28$ - resulting in a total of 140 subjects. All focused on flat feet, although the descriptive terms and methods used to make this diagnosis differed. Rome (2004) used the Foot Posture Index (Redmond 2006) ${ }^{18}$ which is a generally acceptable, if not absolutely valid, measure of foot posture, to diagnose 'excessively pronated' feet. Redmond (2009) supplemented the FPI with Rose's ValgusIndex (Rose 1985) ${ }^{19}$ and a relaxed calcaneal stance position of $>5$ degrees valgus. Esterman (2005) used the arch index (Cavanagh 1987) ${ }^{20}$, an older footprint based technique, and Jung et al 2011 used a relaxed calcaneal stance position of $>4$ degrees \{which is 1 degree less than the value required by Redmond (2009) - and a navicular drop of $>13 \mathrm{~mm}$ to diagnose 'pes planus'. Whilst the navicular drop is a well-described measure, it has been suggested that it must be normalized against foot length to improve validity (Evans 2003). ${ }^{8}$ Variations in the diagnostic criteria used mean that it is conceivable that not all subjects would satisfy the criteria for inclusion in the different studies. Whilst all studies used foot orthoses in some form - either custom made or prefabricated - Jung et al (2011) also investigated the effect of 'short foot exercises' designed to in- 
crease the strength of the intrinsic musculature in combination with foot orthoses.

Rome (2004) investigated the effect of a prefabricated orthotic on 3 balance parameters - mean balance and anterior-posterior and medio-lateral sway measured using the $\mathrm{Ba}$ lance Performance Monitor, in a group of 50 participants. Half of those 50 were allocated to receive prefaricated foot orthoses whilst half acted as controls, and the trial took place over 4 weeks. No significant difference was reported between the control and intervention group for anterior-posterior sway, although a significant difference $(p=0.02)$ was reported for mediolateral sway. Esterman (2005) conducted their evaluation of the effect of prefabricated orthoses on pain, injury, foot health and quality of life, on a group of 47 new Royal Australian Air Force recruits. A computerized random number generator was used to assign 25 subjects to receive $3 / 4$ length prefabricated foot orthoses and 22 to receive no treatment. No significant differences were identified in any variable, although due to only half the treatment group wearing the orthoses for the required time, analysis was modified from two groups to three, with the treatment group divided into one who had worn the devices and one who had not. Redmond (2009) conducted a laboratory based, randomised, crossover trial. Fifteen subjects were recruited and randomized via a sealed envelope system to determine whether they would receive custom fabricated $4 \mathrm{~mm}$ polypropylene orthoses or prefabricated intrinsically posted orthoses first. Baseline measures were obtained, the first orthosis was issued according to the randomisation, and subjects returned to the lab after wearing the first device for two weeks when measures were repeated. Cross-over to the appropriate second device then took place and again participants returned after two weeks for a further set of measurements to be taken.

A broad range of 7 plantar pressure measurement variables were recorded, including peak pressure, maximum mean pressure and maximum force, for 5 discrete plantar foot regions including the heel, midfoot, medial forefoot, lateral forefoot, hallux, and lateral digits. The analysis was performed via a 'masking' procedure that divided the plantar foot area into discrete regions to allow the range of 35 variable / mask combinations to be investigated. Differences were identified relative to the control condition for 11 of the 35 variable /mask combinations, with custom devices demonstrating enhanced changes over prefabricated devices for three variables, although this did not translate to a statistically significant difference.

Therefore, although prefabricated and custom devices seem to produce differences in plantar pressure distribution, the effects do not seem dependent on the type of device.

Jung et al (2011) examined the effect of custom foot orthoses alone or in combination with 'short foot exercises' on the cross sectional area of abductor hallucis, measured using ultrasound, and the strength of flexor hallucis longus, assessed using a digital dynamometer over 8 weeks. A pool of two hundred and forty volunteers were screened using relaxed calcaneal stance position and navicular drop measurement to identify bilateral pes planus, and twenty-eight subjects met all of the inclusion criteria and were randomised into two groups. Group 1 received foot orthoses in isolation, whilst group 2 received instruction on an exercise technique for the intrinsic foot muscles in addition to the foot orthoses. The orthosis was a $1 / 8 \mathrm{inch} / 3 \mathrm{~mm}$ polypropylene standard functional orthosis.Pre-test and post-test measurements of abductor hallucis cross sectional area was assessed using a $7.5 \mathrm{MHz}$ linear array ultrasound probe.

The strength of flexor hallucis longus was measured using a digital dynamometer. Although both groups showed a significant difference from baseline for both cross sectional abductor hallucis area $(\mathrm{p}=0.015)$ and flexor halluces muscle strength $(\mathrm{p}=0.000)$, there was a significant difference in the change observed in the group that performed exercises as well as using custom orthoses (cross section of abductor hallucis $\mathrm{p}=0.008$; flexor hallucis strength $\mathrm{p}=0.008)$.

\section{Risk of bias in included studies}

The methodological quality of the four included studies was poor. Independent assessment of methodological quality of all the included trials using a tool focusing on the five key areas of bias proposed by Cochrane - Selection, Per- 
formance, Detection, Attrition and Reporting, with an additional section provided to note any other areas incurring a risk of bias. Although all studies adopted a randomised controlled trial design, in each case the execution was flawed in at least one of these areas, increasing the probability that the results could be tainted by bias (see characteristic of studies tables).

\section{Selection Bias}

Assessment of selection bias focused on identifying any risk of systematic differences between the groups being compared. It is influenced by the subjects recruited, the randomisation technique employed, and concealment of group allocation.

Subjects: Although all four studies utilised an objective assessment system for diagnosing pes planus, none of the participants in any of the studies were selected due to complaining of persistent pain or functional limitation and were asymptomatic. Rome (2004) states that one hundred and twenty-four subjects were identified, but does not mention the population of origin. Seventy four failed to meet the exclusion criteria leaving 50 participants entering the trial, with demographic data (age, weight, height) suggesting a physically homogenous population. Esterman (2005) recruited

47 Royal Australian Air Force (RAAF) recruits undergoing basic training, with pes planus diagnosed on the basis of footprint assessment using the Arch Index ${ }^{19,20}$.

Entry requirements to the RAAF again suggest a homgenous population, although the level of physical fitness in this cohort may compromise external validity. Redmond (2009) states that fifteen participants, aged 18-45, were recruited through a university clinic via a poster campaign. Exclusion criteria included specific scores on the Foot Posture Index and Rose's Valgus Index, and any current pain or disability so that participants were otherwise healthy.

Although recruitment via clinic posters suggests a patient cohort who may be expected to be experiencing symptoms, the exclusion criteria leaves room for only asymptomatic patients and their reason for attending the clinic is unknown. No further demographic data is provided and therefore the homogeneity of the population is unknown, compromising external validity. This could be considered inconsequential given the limited sample size of 15 which represents a more significant limitation. Jung et al (2011) states that two hundred and forty volunteers were screened at a university, although no further clarification is provided as to whether this refers to university staff, students, or patients attending a clinic.

The application of exclusion criteria, including assessment of foot posture using relaxed calcaneal stance position and navicular drop, and a range of factors related to general health, reduced this pool to twenty-eight subjects. Demographic and anthropometric characteristics were provided. Despite a level of homogeneity within studies, there is substantial heterogeneity across studies, preventing pooling of data, and there exists a high risk of bias in each of the studies (see characteristic of studies tables).

\section{Randomisation}

All studies utilised an acceptable randomisation process. Rome (2004) used randomised tables accessed by an independent observer, Esterman (2005) used a computerized random number generator, and Jung et al (2011) drew cards labelled with group assignment from a pool of cards. Jung et al (2011) provided a comparison of demographic and anthropometric data (age, height, mass, relaxed calcaneal stance position and navicular drop) - and confirmed statistically that there were no significant differences between groups for these variables. This useful confirmatory exercise suggests a successful randomisation procedure. Whilst these three studies used the randomisation procedure for group allocation, Redmond (2009) used sealed-envelope randomisation to allocate the intervention to be used first, adopting a cross-over methodology, with each participant receiving both interventions over the period of the study, with two weeks of use prior to testing for each orthosis. The use of acceptable randomisation techniques incurs a low risk of bias.

\section{Allocation Concealment}

Whilst the randomisation techniques adopted reduce the likelihood of bias, allocation of concealment was not undertaken in three studies, 
incurring a risk of bias. Rome (2004) used an independent assessor to record all measurements, but failed to blind this individual. The Esterman (2005) study was the second part of a larger project that began with a prospective cohort study of recruits. It is unlikely that assessors were blinded to the purpose of subject assignment, intervention allocation or outcome measurement as there is no mention of this in either the first part of the study - a prospective cohort study - in which the randomized trial was nested. Redmond (2009) provided no details of concealment and it seems likely that the authors were responsible for data capture and analysis from the statement of authors' contributions at the end of the article. Jung et al (2011) state that all tests were administered by the same investigators, that casts for custom made orthoses were obtained by the principal investigator, and that the investigator was blinded to allocation of intervention. The details of how this was achieved were not provided; however, particularly in relation to the principal investigators weekly meetings with subjects to ensure that the exercises were being done correctly - which incurs a chance of contamination.

All studies, therefore, were deemed to be at risk of selection bias due to a compromise to at least one area that contributes to that dimension of risk (see characteristic of studies tables 2-5).

\section{Performance Bias}

Assessment of performance bias focused on identifying whether blinding of study participants and/or personnel took place, which helps ensure that compared groups receive a similar amount of attention, ancillary treatment, and diagnostic investigations.

Rome (2004) did not use a placebo intervention, and therefore one group knew that it had received orthoses, whilst the other group did not receive an orthoses and were aware of this. An independent observer was used to record all measurements, but was not blinded. Esterman (2005) provided orthotics to approximately half of subjects at random, and these were fitted by a qualified orthotist.

No information was provided on the information provided to this orthotist or their inde- pendence from the study. The orthoses were chosen after consultation with the RAAF podiatrist, senior medical officer, physical training instructors and orthotic supplier.

This suggests an open and transparent study with the absence of information on blinding providing no reason to believe that appropriate steps were taken. Redmond (2009) does not mention any blinding of participants to the condition being tested, and the lead authors' supervision of data collection suggests that there was no assessor blinding. Jung et al 2011 state that all tests were administered by the same investigators, but also reveal that the principal investigator manually assisted - according to individual ability - with maintaining the medial longitudinal arch during short foot exercises for the first two weeks. Participants in the 'orthoses only' group were directly asked not to take part in any foot and ankle exercise programme, which implies that the 'exercise' group received close attention.

It is clear that the subjects were not blinded to the intervention and that the investigator played a key role in evaluating the progress of the trial. A high risk of performance bias was therefore evident in all 4 studies.

\section{Detection Bias}

Assessment of detection bias focused on determining whether there were systematic differences between groups in how outcomes were determined.

Outcomes were assessed in a consistent way for the different groups in all included studies. As previously noted in relation to performance bias, assessors were not blinded in any trial, representing a potential bias. However, a variety of outcome measures were used, ranging from pain, functional limitation, and general health status aspects of several quality-of-life questionnaires such as FHSQ and WHOQOL (Esterman 2005), to plantar pressure distribution (Redmond 2009), postural stability (Rome 2004) and muscle power / cross-sectional area (Jung 2011). It is generally accepted that a failure to blind outcomes assessors is especially relevant with subjective outcomes, and therefore the use of a range of objective measurements in all but the Esterman (2005) study suggests that it is unlikely that the failure to blind 
assessors exerted an influence due to the objective nature of the measurements recorded. Esterman (2005) included a range of outcomes that included injury rate, and provided a clear definition of injury as an episode that required $>3$ days off training and so a mix of objective and subjective outcomes were included. The issues associated with the lack of assessor blinding, and incomplete information provided in relation to self- or assisted completion of questionnaires makes it difficult to judge the risk of detection bias with Esterman (2005). The use of objective outcomes in the three remaining studies suggests a low risk of detection bias.

\section{Attrition Bias}

Assessment of attrition bias considers whether there may be systematic differences between groups in withdrawals from a study The four studies included in the review were performed in well-defined, and well-controlled, environments - largely due to their experimental nature. This minimised attrition in all studies, but did not eliminate the issue. Notably, Esterman (2005) was conducted amongst recruits to the RAAF during their basic training. Whilst no subjects were lost to follow up in the conventional sense, the level of use varied. Twenty of 25 reported frequency of use, with 10 of the 20 wearing them all or most of the time and the remainder stating that they did not use them regularly. This variable level of engagement with the intervention incurred a high risk of bias. Rome (2004) achieved a 100\% follow up. Likewise, Redmond (2009) achieved a 100\% completion rate for their 15 participants.

Jung et al (2011) do not mention attrition, although the 8 week duration involving just 28 subjects suggests that it may be feasible that there was no attrition and there seems to be complete outcome data in this and all other studies excepting Esterman 2005. Esterman (2005) may be judged to have a high risk, whilst the remaining studies have a low risk, of attrition bias.

\section{Reporting Bias}

Reporting bias focuses on whether there could be systematic differences between reported and unreported findings. The nature of the included studies - with closely defined, largely objecti- ve, outcomes - protects against reporting bias in three of the four studies and all outcomes were reported. Rome (2004), Redmond (2009) and Jung et al (2011) each used a small number of objective outcomes which were highly specialised. For example, Rome (2004) focused on balance assessment, Redmond 2009 focused on plantar pressure distribution and Jung et al 2011 assessed muscle power and muscle cross-sectional area, making reporting straightforward, and all variables are easily traced and identifiable as fully reported. Although Esterman (2005) used a larger number of outcomes, of which some were self-completed questionnaires, there also seems a low risk of reporting bias.

\section{Other Bias}

Other biases may reflect any problems not covered under the five main headings.

In addition to the risks to bias identified in the key areas, several other influences falling out-with these also impacted on study quality. Esterman (2005) used prefabricated orthoses that were heat moulded and issued by an orthotist, but the manufacturers protocol was not used in that a hairdryer and not a heat gun was used. The orthoses are therefore unlikely to have reached the suggested heat-moulding temperature. The influence this may have had on results is unknown, but it does represent a flaw in the protocol. A potentially more important bias is the use of a cross-over design by Redmond (2009) to assess the relative effect of custom and pre-fabricated orthoses on plantar pressures. The study recruited 15 subjects and conducted baseline measurements before randomly issuing either custom or pre-fabricated orthoses. These devices were used for two weeks before measurements were repeated, whereupon subjects crossed over to the second device. A similar two week use period preceded a final set of measurements. Cross-over trials are deemed appropriate for assessment of interventions that have temporary effects, for stable conditions. Where there is a risk of the condition changing over the study period, or of the intervention producing an effect that can be carried-over to interfere with the second intervention, such a design is unsuitable unless a washout period is used, where the effect of 
one intervention is allowed time to become negligible before the second is introduced. The failure to include any washout period prior to the introduction of the second intervention may theoretically incur a risk of bias.

The requirement for, and optimal length of, a wash-out period requires investigation to determine the suitability of this design feature. Such risks to bias compound the risks occurring in the key areas, and serve to further highlight the inadequacy of the research performed on interventions for pes planus.

\section{Effects of interventions}

We included four studies in the Review that met the inclusion criteria [Outcome Measures table below].

Do the treatment interventions work? It is clear than none of the interventions as specified in the Review have any significant impact on the short or long term prognosis of this condition. The Interventions and the resultant outcome measures in each of the trials has unknown clinical utility.

\section{DISCUSSION}

Although there is an extensive literature base concerning the conservative treatment of pes planus in adults, it is not possible to draw any conclusions regarding the effectiveness of interventions.
This is the result of several clear, recurrent, issues associated with the methods used and the outcome measures selected in the research base. General methodological quality is poor, with a high risk of bias in at least two key areas for each study. Although the included studies can be seen to use some techniques to reduce risk of bias, these typically relate to inexpensive and easier to implement techniques. For example, it is common to see robust randomization techniques being used, perhaps because of the relative ease with which this can be achieved and the minimal cost incurred. Conversely, more expensive and complex techniques for reducing risk of bias, such as the use of independent, blind, assessors, are not commonly used. Such techniques would increase the resources required to run a study - potentially reducing their financial viability. Adequate resourcing is vital if core issues like this are to be addressed or methodological quality will continue to be poor, and the risk of bias will continue to be high.

Across the pes planus literature a vast range of outcome measures have been reported, including lower limb muscle activity (Franattovich et al 2012), quadriceps and gluteus medius electromyography (Hertel 2005), the quadriceps femoris angle (Kuhn 2002), gait pattern (Kulcu et al 2007), tibialis posterior activation (Kulig 2005), and ground reaction forces (Miller 1996). This is at least in part attributable to the duration of the trials and

Table 1. Outcome measurements used.

\begin{tabular}{ll} 
& Outcome Measures \\
\hline Esterman 2005 & $\begin{array}{l}\text { General foot health scale (Foot Health Status Questionnaire) and a quality of life } \\
\text { and physical health scale (World } \\
\text { Health Organisation Quality of Life Questionnaire) }\end{array}$ \\
\hline Jung et al 2011 & $\begin{array}{l}\text { Cross sectional area of the abductor hallucis muscle and the strength of the flexor } \\
\text { hallucsi muscle were measured }\end{array}$ \\
\hline Redmond 2009 & Pressures and forces measured by an in-shoe measuring system \\
\hline Rome 2004 & Anterior-Posterior and Medial-Lateral Postural Sway \\
\hline
\end{tabular}


difficulties in accessing homogenous symptomatic subjects for long-term follow up. Pes planus is a chronic,multi-dimensional, morbidity theoretically associated with a variety of signs and symptoms. The potential manifestations of the condition are therefore manifold, including pain, functional limitation, and gait variables, including kinematic, kinetic and EMG variables. This presents numerous opportunities for experimental research. Focusing on gait variables obviates the need for symptomatic subjects and allows short-term studies evaluating the effect of interventions on gait performance without considering the effect on pain and functional limitation over longer time periods. Gait-related variables are, however, unproven proxy measures of effectiveness with an ill-defined association with pain and functional limitation. This focus on experimental research - undoubtedly driven by convenience - has been detrimental to the body of literature and the ability to draw conclusions from that literature. The result is extreme heterogeneity in the outcomes described in the literature base, Table 1 below, which prevents meta-analysis and provides no indication of the effect of interventions on clinically important outcomes. Consistent with the focus of the Cochrane Collaboration, patient oriented outcomes such as pain and functional limitation is required, and recruiting subjects with symptomatic pes planus should be prioritized.

\section{CONCLUSIONS}

Whilst there may be some benefit associated with the interventions described in the included studies, there is insufficient evidence from randomized controlled trials to determine which conservative treatment is the most appropriate for the management of pes planus in adults. The quality of the research is poor, with substantial heterogeneity between studies
- in terms of participants, interventions and outcomes. Before further research is conducted consensus should be achieved on the types of participants, interventions and outcome measures that should be used to permit future meta-analysis to be performed.

\section{Implications for practice}

Based on the results of this review we conclude there is no available evidence from randomised controlled trials to determine which method of treatment is the most appropriate for the treatment of adult pes planus. There is no evidence on the use of strapping, footwear modification or stretching. There is only limited evidence for the effectiveness of foot orthoses in treatment of adult pes planus: the evidence is characterised by a focus on asymptomatic subjects rather than subjects experiencing symptoms, selection of a range of proxy outcome measures as opposed to patient-oriented outcomes, and long-term implications are not understood due to the short time periods used. The extent to which to which foot orthoses may alter foot function, quality of life and reduce pain, however, are still to be determined

\section{Implications for research}

Despite a large literature base, issues with study quality, the use of experimental designs that assess asymptomatic subjects, and the evaluation of a range of outcome measures with an often ill-defined association with patient oriented outcomes prevent any conclusions from being drawn.

New trials should investigate the long-term benefits of foot orthoses compared with other non-surgical interventions such as stretching exercises, strengthening or strapping. A reasonable length of follow-up (at least one year or above) is required to detect recurrence and long term outcome. If foot orthoses are effective then a comparison between non-surgical interventions and surgical interventions should also be considered.

\section{REFERENCES}

1. Rome K, Brown CL. Randomized clinical trial into the impact of rigid foot orthoses on balance parameters in excessively pronated feet. Clinical Rehabilitation 2004;18: 624-30. 
2. Redmond, A. C, K. B. Landorf, Keenan AM. Contoured, prefabricated foot orthoses demonstrate comparable mechanical properties to contoured, customised foot orthoses: a plantar pressure study. Journal of Foot \& Ankle Research 2009;2(20):doi:10,1186/1757-1146-2-20.

3. Esterman A, Pilotto L. Foot shape and its effect on functioning in Royal Australian Air Force recruits. Part 2: pilot, randomized, controlled trial of orthotics in recruits with flat feet. Military Medicine 2005;170:629-33.

4. Jung, D. Y, E. K. Koh, et al.Effect of foot orthoses and short-foot exercise on the cross-sectional area of the abductor hallucis muscle in subjects with pes planus: A randomized controlled trial. Journal of Back and Musculoskeletal Rehabilitation 2011;24(4):225-231.

5. Chen MJL, Chen CPC, lew H1, Hsich W, Yang W, Tang SFT. Measurement of forefoot varus angle by laser technology in people with flexible flatfoot. Journal of Physical Medicine and Rehabilitation 2003;82:842-6.

6. Curran SA, Upton D, Mathieson I, Learmonth ID. A cross-sectional survey to formluate clinical patellofemoral alignment and foot posture categories. Journal of Orthopaedics and Sports Physical Therapy. 2010; Vol. 101: S21-22.

7. Tareco JM, Miller NH, MacWilliams BA, Michelson JD. Defining flatfoot. Foot \& Ankle International 1999;20: 456-60.

8. Evans AM, Copper AW, Schartbillig RW, Scutter SD, Williams MT. Reliability of the foot posture index and traditional measures of foot position. Journal of the American Podiatric Medical Association 2003;93:205-13

9. Mankey MG. A classication of severity with an analysis of causative problems related to the type of treatment problems related to the type of treatment. Foot and Ankle Clinics 2003;8:46171.

10. Staheli IT. Evaluation of planovalgus foot deformity with special reference to natural history reference to natural history. Journal of American Podiatric Medical Association 1987;77:2-6.

11. Barry RJ, Scranton PE. Flat feet in children. Clinical Orthopaedics and Related Research 1983;181:68-75.

12. McCrea JD. Pediatric Orthopedics of the Lower Extremity. New York: Futura Publiching, 1985.

13. Root, Orien, Weed. Normal and Abnormal Function of the Foot. Vol. 2, Los Angeles: Clinical Biomechanics Corporation, 1977.

14. Kirby. Rotational equilibrium across the subtalar joint axis. $J$ Am Podiatr Med Assoc. 1989;79:1-14.

15. Clarke TE, Frederick EC, Hamill C. Sports shoes and playing surfaces. Champaign, 1984.

16. Kirby KA, Green DR. Evaluation and nonoperative management of Pes Valgus. In: DeValentine SJ editor(s). Foot and ankle disorders in children. New York: Churchill Livingstone, 1992.

17. Robinson KA, Dickersin K. Development of a highly sensitive search strategy for the retrieval of reports of controlled trials using PubMed. International Journal of Epidemiology 2002;3:150-3.

18. Redmond AC, Crosbie J, Ouvrier RA. Development and validation of a novel rating system for scoring standing foot posture: the Foot Posture Index. Clinical Biomechanics 2006;21:89-98.

19. Rose GK, Welton EA, Marshall T. The diagnosis of flatfoot in the child. Journal of Bone and Joint Surgery (Br) 1985;67- b(1):71-78.

20. Cavanagh PR, Rodgers MM. The Arch Index: A useful measure from footprints. Journal of Biomechanics 1987;20 (5):547-551

21. Higgins JPT, Green S. Assessing Risk of Bias in included studies. In: Higgins JPT, Green: Cochrane Handbook for Systematic Reviews of Interventions, Version 5.1.0 Part 2, Chapter 8

22. Jadad AR, Moore RA, Carroll D, Jenkinson C, Reynolds DJM, Gavaghan DJ, McQuay H. Assessing the quality of reports of randomized clinical trials: Is blinding necessary? Controlled Clinical Trials 1996; 17: 1-12. 
23. Franettovich, et al.A comparisin of augmented low-dye taping and ankle bracing on lower limb muscle activity during walking in adults with flat-arched foot posture. Journal of Science and Medicine in Sport 2012;15(1):8-13.

24. Hertel J, Sloss BR, Earl JE. Effect of foot orthotics on quadriceps and gluteus medius electromyogaphic activity during selected exercises. Archives of Physical Medicine and Rehabilitation 2005;86:26-30.

25. Kuhn DR, Yochum DC, Cherry AR, Rodgers SS. Immediate changes in the quadriceps femoris angle after insertion of an orthotic device. Journal of Manipulative and physiological Therapeutics 2002;25:465-70.

26. Kulcu, et al.Immediate effects of silicone insoles on gait pattern in patients with flexible flatfoot. Foot \& Ankle International 2007;28(10):1053-1056.

27. Kulig K, Burnfield JM, Reischl S, Reqejo SM, Blanco CE, Thordarson DB. Effect of foot orthoses on tibialis posterior activation in persons with pes planus. Medicine \& Science in Sports \& Exercise 2005;37:24-9.

28. Miller CD, Laskowski ER, Suman VJ. Effect of corrective rearfoot orthotic devices on ground reaction forces during ambulation. Mayo Clinical Proceedings 1996;71:757-62.

\section{REFERENCES TO STUDIES INCLUDED IN THIS REVIEW}

\section{Esterman 2005}

Esterman A, Pilotto L. Foot shape and its effect on functioning in Royal Australian Air Force recruits. Part 2: pilot, randomized, controlled trial of orthotics in recruits with flat feet. Military Medicine 2005; 170:629-33.

\section{Jung et al 2011}

Jung, D. Y, E. K. Koh, et al.Effect of foot orthoses and short-foot exercise on the cross-sectional area of the abductor hallucis muscle in subjects with pes planus: A randomized controlled trial. Journal of Back and Musculoskeletal

Rehabilitation 2011;24(4):225-231.

\section{Redmond 2009}

Redmond, A. C, K. B. Landorf, Keenan AM. Contoured, prefabricated foot orthoses demonstrate comparable mechanical properties to contoured, customised foot orthoses: a plantar pressure study. Journal of Foot \& Ankle Research 2009;2(20):doi:10,1186/1757-1146-2-20.

\section{Rome 2004}

Rome K, Brown CL. Randomized clinical trial into the impact of rigid foot orthoses on balance parameters in excessively pronated feet. Clinical Rehabilitation 2004;18:

624-30.

\section{REFERENCES TO STUDIES EXCLUDED FROM THIS REVIEW}

\section{Alvarez 2006}

Alvarez, R. G, A. Marini, et al.Stage I and II posterior tibial tendon dysfunction treated by a structured nonoperative management protocol: an orthosis and exercise program.. Foot \& Ankle International 2006;1(27):2-8.

\section{Cunningham 2008}

Cunningham. Effects of orthotic intervention during running among individuals with functional flatfoot. MSc Canada, Wilfrid Laurier University (Canada). 2008. 


\section{Du 2008}

$\mathrm{Du}$, et al.Foot plantar pressure and gait features of flatfoot and normal foot. Journal of Clinical Rehabilitative Tissue Engineering and Research 2008;12(46):9058-9061.

\section{Franettovich et al 2012}

Franettovich, et al.A comparisin of augmented low-dye taping and ankle bracing on lower limb muscle activity during walking in adults with flat-arched foot posture.

Journal of Science and Medicine in Sport 2012;15(1):8-13.

\section{Hertel 2005}

Hertel J, Sloss BR, Earl JE. Effect of foot orthotics on quadriceps and gluteus medius electromyogaphic activity during selected exercises. Archives of Physical Medicine and Rehabilitation 2005;86:26-30.

\section{Hurd et al 2010}

Hurd, et al.Comparative biomechnical effectiveness of over the- counter devices for individuals with a flexible flatfoot secondary to forefoot varus. Clinical Journal of Sports Medicine 2010;20(6):428-435.

\section{Jung et al 2009}

Jung, et al.Effect of medical arch support on displacement of the myotendinous junction of the gastrocnemius during standing wall streching. The Journal of Orthopaedic and Sports Physical Therapy 2009;39(12):867-874.

\section{Ki et al 2008}

$\mathrm{Ki}$, et al.Comparison of plantar pressure distribution patterns between foot orthoses by CAD-CAM and foam impression methods. Prosthetics and Orthotics International

2008;32(3):356-362.

\section{Kosashvili et al 2008}

Kosashvili, et al.The correlation between pes planus and anterior knee or intermittent low back pain. Foot \& Ankle International 2008;29(9):910-913.

\section{Kuhn 2002 \{published data only\}}

Kuhn DR, Yochum DC, Cherry AR, Rodgers SS. Immediate changes in the quadriceps femoris angle after insertion of an orthotic device. Journal of Manipulative and physiological Therapeutics 2002;25:465-70.

\section{Kulcu et al 2007}

Kulcu, et al.Immediate effects of silicone insoles on gait pattern in patients with flexible flatfoot. Foot \& Ankle International 2007;28(10):1053-1056.

\section{Kulig 2005}

Kulig K, Burnfield JM, Reischl S, Reqejo SM, Blanco CE, Thordarson DB. Effect of foot orthoses on tibialis posterior activation in persons with pes planus. Medicine \& Science in Sports \& Exercise 2005;37:24-9.

\section{Miller 1996}

Miller CD, Laskowski ER, Suman VJ. Effect of corrective rearfoot orthotic devices on ground reaction forces during ambulation. Mayo Clinical Proceedings 1996;71:757-62.

\section{Murley et al 2010}

Murley, et al.Do foot orthosis change lower limb muscle activity in flat-arched feet towards a pattern observed in normal-arched feet?. Clinical Biomechnics 2010;25(7): 728-736.

\section{Nordsiden et al 2010}

Nordsiden, et al.The effect of 3 foot pads on lantar pressure of pes planus foot type. Journal of Sports Rehabilitation 2010;19(1):71-85. 
n Y S Lou et al 2010

$\mathrm{n}$ Y S Low, et al.Effects of foot orthoses on gait patterns of flat feet patients. Clinical Biomechnics 2010;25(3):265-270.

\section{Radford et al 2006}

Radford, et al.The effect of low-dye taping on kinematic, kinetic and electromyographic variables. Journal of orthopaedics and Sports Physical Therapy 2006;36(4): 232-241.

\section{Vicenzino et al 2008}

Vicenzino, et al.Foot orthoses and physiotherapy in the treatment of patellofemoral pain syndrome: a randomised clinical trial. BMC musculoskeletal disorders 2008;27(337: a1735):doi:10.1136/bmj.a1735.

\section{CHARACTERISTICS OF THE STUDIES REVIEWED}

\section{Esterman 2005: Table 2}

\begin{tabular}{ll} 
Methods & Single blinded, randomised, military clinical trial. \\
\hline Participants & Location: Australia. Air Force Base, No 1 Research Training Unit, Edinburgh, \\
& South \\
& Australia. Recruitment period: 2004 \\
& 230 subjects recruited with 47 meeting criteria; Inclusion criteria: \\
& Attending basic training. \\
& Exclusion criteria: \\
& Existing foot orthoses. \\
Interventions & Flexible $3 / 4$ length functional foot orthotic. A 40 rearfoot wedge, 40 forefoot wedge, \\
Second, third, and fourth dorsal metatarsal alignment and 15 mm calcaneal heel cup
\end{tabular}

\section{Risk of Bias}

\begin{tabular}{|c|c|c|}
\hline Bias & $\begin{array}{l}\text { Authors' } \\
\text { judgement }\end{array}$ & Support for judgement \\
\hline $\begin{array}{l}\text { Blinding (performance bias and } \\
\text { detection bias) } \\
\text { All outcomes }\end{array}$ & Low risk & $\begin{array}{l}\text { Participants randomly assigned to one of } \\
\text { two groups by the use of randomized tables } \\
\text { by an independent observer. All participants } \\
\text { treated according to same protocol }\end{array}$ \\
\hline $\begin{array}{l}\text { Blinding of participants and per- } \\
\text { sonnel } \\
\text { (performance bias) } \\
\text { All outcomes }\end{array}$ & Unclear risk & $\begin{array}{l}\text { No information provided on blinding the or- } \\
\text { thotist who provided orthoses, and no men- } \\
\text { tion of blinding of participants }\end{array}$ \\
\hline $\begin{array}{l}\text { Allocation concealment (selec- } \\
\text { tion bias) }\end{array}$ & Unclear risk & $\begin{array}{l}\text { No information provided on allocation con- } \\
\text { cealment. }\end{array}$ \\
\hline $\begin{array}{l}\text { Blinding of outcome assessment } \\
\text { (detection bias) } \\
\text { All outcomes }\end{array}$ & Unclear risk & $\begin{array}{l}\text { No information provided on blinding of as- } \\
\text { sessor }\end{array}$ \\
\hline
\end{tabular}




\begin{tabular}{lll}
\hline $\begin{array}{l}\text { Random sequence generation } \\
\text { (selection bias) }\end{array}$ & Low risk & $\begin{array}{l}\text { Participants randomly assigned to one of two } \\
\text { groups by the use of randomized tables by an } \\
\text { independent observer }\end{array}$ \\
\hline $\begin{array}{l}\text { Incomplete outcome data (attri- } \\
\text { tion bias) }\end{array}$ & High risk & $\begin{array}{l}\text { Inconsistent use of orthoses: 'Notably, only } \\
\text { one-half of the recruits provided with orthot- } \\
\text { ics wore them most or all of the time' }\end{array}$ \\
$\begin{array}{l}\text { Selective reporting (reporting } \\
\text { bias) }\end{array}$ & Low risk & $\begin{array}{l}\text { Battery of measures identified at the start of } \\
\text { the study all considered in results }\end{array}$ \\
Other bias & Unclear risk & $\begin{array}{l}\text { Use of orthotic heat moulding procedure not } \\
\text { in line with manufacturers recommendations }\end{array}$ \\
\hline
\end{tabular}

\section{Jung et al 2011: Table 3}

\begin{tabular}{ll} 
Methods & A randomized controlled trial \\
Participants & $\begin{array}{l}\text { Located in South Korea. Two hundred and forty volunteers were screened to iden- } \\
\text { tify pes planus. They were included if the resting calcaneal stance position was } \\
\text { more than } 4 \text { degrees + if their navicular drop exceeded } 13 \mathrm{~mm} \text {. They were excluded } \\
\text { if they had a history of foot and ankle surgery, a systemic disease that might have } \\
\text { an effect on the foot and if they were cognitively impaired. } \\
\text { Twenty eight participants were recruited and were randomly assign to one of two } \\
\text { groups. }\end{array}$ \\
$\begin{array}{l}\text { One foot orthoses group and a foot orthoses group plus a short-foot exercise regime. } \\
\text { Interventions }\end{array}$ & $\begin{array}{l}\text { Cross sectional area of the abductor halluces muscle and the strength of the flexor } \\
\text { hallucsi muscle were measured. }\end{array}$ \\
\hline Notes & No sources of funding identified.
\end{tabular}

\section{Risk of Bias}

\begin{tabular}{|c|c|c|}
\hline Bias & $\begin{array}{l}\text { Authors' } \\
\text { judgement }\end{array}$ & Support for judgement \\
\hline $\begin{array}{l}\text { Blinding (performance bias and } \\
\text { detection bias) } \\
\text { All outcomes }\end{array}$ & High risk & $\begin{array}{l}\text { Principal investigator involved in pro- } \\
\text { viding clinical support for assessor, ex- } \\
\text { posing the method to a significant risk } \\
\text { of bias }\end{array}$ \\
\hline $\begin{array}{l}\text { Blinding of participants and per- } \\
\text { sonnel (performance bias) } \\
\text { All outcomes }\end{array}$ & High risk & $\begin{array}{l}\text { PI and subjects clearly not blinded to } \\
\text { allocation, and PI took active role in } \\
\text { supporting training in one of the inter- } \\
\text { ventions: } \\
\text { 'According to the level of individual } \\
\text { ability, } \\
\text { the principal investigator manually as- } \\
\text { sisted with maintaining the MLA height } \\
\text { during short foot exercises' }\end{array}$ \\
\hline $\begin{array}{l}\text { Allocation concealment (selection } \\
\text { bias) }\end{array}$ & high risk & $\begin{array}{l}\text { PI closely involved in supporting clini- } \\
\text { cians recording measurements }\end{array}$ \\
\hline
\end{tabular}




\begin{tabular}{lll}
$\begin{array}{l}\text { Blinding of outcome assessment } \\
\text { (detection bias) } \\
\text { All outcomes }\end{array}$ & High risk & PI involved in enacting study protocol \\
$\begin{array}{l}\text { Random sequence generation } \\
\text { (selection bias) }\end{array}$ & Low risk & $\begin{array}{l}\text { Low risk Subjects randomized via the } \\
\text { use of labelled cards }\end{array}$ \\
$\begin{array}{l}\text { Incomplete outcome data (attri- } \\
\text { tion bias) } \\
\text { All outcomes }\end{array}$ & Low risk & Full outcome data provided \\
$\begin{array}{l}\text { Selective reporting (reporting } \\
\text { bias) }\end{array}$ & Low risk & $\begin{array}{l}\text { Results reported in accordance with } \\
\text { method }\end{array}$ \\
\hline Other bias & Low risk & \\
\hline
\end{tabular}

\section{Redmond 2009: Table 4}

\begin{tabular}{ll} 
Methods & A randomised cross-over trial \\
Participants & $\begin{array}{l}\text { Located in Australia. Participants recruited via a poster campaign located in an Aus- } \\
\text { tralian polyclinic. Study was undertaken between Oct } 2002 \text { and July 2003. Fifteen } \\
\text { participants, aged between } 18-45 \text { who justified the inclusion criteria were recruited: } \\
\text { relaxed calcaneal stance position of greater than } 5 \text { degrees valgus + a foot posture } \\
\text { index of greater than eight with a max of } 16+\text { a score on Rose's Valgus Index of } \\
\text { greater than } 18 \\
\text { The exclusion criteria included a history of bony surgery or a systemic disorder }\end{array}$ \\
\hline Interventions & semi-rigid customised orthosis and a semi-rigid, contoured, prefabricated orthoses \\
\hline Outcomes & Pressures and forces measured by an in-shoe measuring system \\
\hline Notes & $\begin{array}{l}\text { The study was funded by the University of Western Sydney Research Grants } \\
\text { Scheme } \\
\text { (Australian Research Council Small Grants Scheme) }\end{array}$ \\
\hline
\end{tabular}

\section{Risk of Bias}

\begin{tabular}{|c|c|c|}
\hline Bias & $\begin{array}{l}\text { Authors' } \\
\text { judgement }\end{array}$ & Support for judgement \\
\hline $\begin{array}{l}\text { Blinding (performance bias and } \\
\text { detection bias) } \\
\text { All outcomes }\end{array}$ & Low risk & $\begin{array}{l}\text { Sealed envelope randomisation, study pro- } \\
\text { tocol applied } \\
\text { to all participants }\end{array}$ \\
\hline $\begin{array}{l}\text { Blinding of participants and per- } \\
\text { sonnel }\end{array}$ & Unclear risk & $\begin{array}{l}\text { No information provided on blinding of cli- } \\
\text { nician or subjects }\end{array}$ \\
\hline
\end{tabular}

(performance bias)

All outcomes

Allocation concealment (selection Unclear risk Level of concealment unknown
bias)




Blinding of outcome assessment $\quad$ Unclear risk
(detection bias)

\begin{tabular}{lll}
$\begin{array}{l}\text { Random sequence generation } \\
\text { (selection bias) }\end{array}$ & Low risk & $\begin{array}{l}\text { Cross-over study investigating two inter- } \\
\text { ventions in the same subjects }\end{array}$ \\
\hline $\begin{array}{l}\text { Incomplete outcome data (attrition } \\
\text { bias) }\end{array}$ & Low risk & $\begin{array}{l}\text { All participants completed the study, pro- } \\
\text { viding complete data }\end{array}$
\end{tabular}

All outcomes

$\begin{array}{lll}\text { Selective reporting (reporting bias) Low risk } & \begin{array}{l}\text { A priori stated outcomes presented in re- } \\ \text { sults }\end{array}\end{array}$

Other bias $\quad$ Unclear risk $\quad$ Cross-over designs must utilise an effective 'wash-out' period to minimise the influence of 'carry-over' effects.

Paragraph 3 of 'Data Capture' section states that 'Participants were then randomised according to a computer generated randomisation protocol, to wear one type of orthosis for at least two weeks prior to returning for plantar pressure and force measures. Participants then crossed over to the alternative orthosis and repeated the two week run-in period before returning for further measurement'. This indicates that there may have been unequal 'run-in' times, with no washout period

\section{Rome 2004: Table 5}

\begin{tabular}{ll} 
Methods & Single blinded, randomised, laboratory-based clinical study. \\
Participants & Location: UK. University Laboratory, Middlesbrough. Recruitment period: 2004 \\
& 124 subjects recruited with 50 meeting criteria via advertisements (20 men and 30 \\
women) age range 18-40. \\
Inclusion criteria: \\
Asymptomatic pes planus Normal gait pattern, normal foot anatomy. \\
Exclusion criteria: \\
No previous lower limb or spinal surgical procedure, no H/V, no ligamentous in- \\
stability or injury in knees or ankles, no pain in lower extremities or back, previous \\
foot orthoses; \\
ess than 5 on Foot Posture Index. \\
Semi-rigid functional foot orthotic constructed from a high-density EVA shell with \\
a \\
anterventions \\
shore-value of 700, rearfoot wedge made from low-density EVA with a shore value \\
of 200. 50 rearfoot wedge and 00 forefoot wedge. \\
Anterior-Posterior and Medial-Lateral Postural Sway. \\
Outcomes & $\begin{array}{l}\text { Authors acknowledge the support of the orthotic company in supplying the or- } \\
\text { thoses utilised in the study and stress there was no other additional support from } \\
\text { the orthoric company. }\end{array}$ \\
\hline Notes &
\end{tabular}




\section{Risk of bias}

\begin{tabular}{|c|c|c|}
\hline Bias & Authors' judgement & Support for judgement \\
\hline $\begin{array}{l}\text { Blinding (performance bias and } \\
\text { detection bias) } \\
\text { All outcomes }\end{array}$ & Low risk & $\begin{array}{l}\text { Randomization by use of randomized } \\
\text { tables by an independent observer }\end{array}$ \\
\hline $\begin{array}{l}\text { Blinding of participants and per- } \\
\text { sonnel (performance bias) } \\
\text { All outcomes }\end{array}$ & Unclear risk & $\begin{array}{l}\text { No information provided on blinding of } \\
\text { participants; independent observer re- } \\
\text { sponsible for taking measurements was } \\
\text { not blinded }\end{array}$ \\
\hline
\end{tabular}

$\begin{array}{lll}\begin{array}{l}\text { Allocation concealment (selection } \\ \text { bias) }\end{array} & \text { High risk } & \begin{array}{l}\text { Sequence generation appropriate; no } \\ \text { information on participant blinding; ob- } \\ \text { server not blinded }\end{array} \\ \begin{array}{l}\text { Blinding of outcome assessment } \\ \text { (detection }\end{array} & \text { High risk } & \begin{array}{l}\text { Independent observer recorded all } \\ \text { measurements but was not blinded }\end{array}\end{array}$

bias)

All outcomes

$\begin{array}{lll}\begin{array}{l}\text { Random sequence generation } \\ \text { (selection bias) }\end{array} & \text { Low risk } & \begin{array}{l}\text { Randomized tables used by an inde- } \\ \text { pendent observer }\end{array} \\ \begin{array}{l}\text { Incomplete outcome data (attrition } \\ \text { bias) }\end{array} & \text { Low risk } & \begin{array}{l}\text { Complete dataset provided, with no } \\ \text { drop Out }\end{array}\end{array}$

All outcomes
Selective reporting (reporting bias) Low risk A priori identified outcomes reported in results

Other bias

Low risk

\section{Characteristics of excluded studies: Table 6}

\begin{tabular}{ll}
\hline Study & Reason for exclusion \\
\hline Alvarez 2006 & Focused on tibials posterior dysfunction \\
\hline Cunningham 2008 & Experimental research \\
\hline Du 2008 & Experimental, not focussed on therapy \\
\hline Franettovich et al 2012 & Experimental \\
\hline Hertel 2005 & Non-randomised clinical trial \\
\hline Hurd et al 2010 & Experimental \\
\hline Jung et al 2009 & Experimental and subjects not randomised \\
\hline Ki et al 2008 & Experimental, not randomised or controlled \\
\hline
\end{tabular}




\begin{tabular}{|ll|}
\hline Kosashvili et al 2008 & Retrospective study \\
\hline Kuhn 2002 & Non-randomised clinical trial \\
\hline Kulcu et al 2007 & Not randomised or controlled \\
\hline Kulig 2005 & $\begin{array}{l}\text { Randomised clinical trial but relating to tibialis posterior dysfunction } \\
\text { Randomised clinical trial conducted in a laboratory setting. Data was } \\
\text { analysed on single subjects }\end{array}$ \\
\hline n Y S Lou et al 2010 & Not randomised or focused on interventions \\
\hline Murley et al 2010 & experimental, not controlled \\
\hline Nordsiden et al2010 & Experimental \\
\hline Radford et al 2006 & systematic review of experimental studies \\
\hline Vicenzino et al 2008 & Focussed on PFP \\
\hline
\end{tabular}

